DOI 10. 18307/2018. 0605

(c) 2018 by Journal of Lake Sciences

\title{
白洋淀沉积物一沉水植物一水系统重金属污染分布特征
}

\author{
薛培英 ${ }^{1}$, 赵全利 ${ }^{2}$, 王亚琼 ${ }^{1}$, 耿丽平 $^{1}$, 陈苗苗 ${ }^{3}$, 王晓美 ${ }^{1}$, 王殿武 ${ }^{1}$ \\ ( 1 : 河北农业大学资源与环境科学学院/河北省农田生态环境重点实验室,保定 071000) \\ (2:河北农业大学教学试验场,保定 071000) \\ (3:河北农业大学科学技术研究院,保定 071000)
}

摘 要: 通过对白洋淀沉水植物及对应沉积物和水中 $\mathrm{Cd} 、 \mathrm{~Pb} 、 \mathrm{As}$ 含量测定, 以期揭示白洋淀沉积物一沉水植物一水系统中 重金属污染状况及分布规律,明确不同沉水植物对重金属的富集能力. 结果表明,地表水 $\mathrm{Cd} 、 \mathrm{~Pb} 、 \mathrm{As}$ 浓度均符合我国地表 水 $\mathrm{I}$ 类水质标准, 不同采样区重金属浓度差异不显著. 上覆水 $\mathrm{Pb}$ 浓度显著高于地表水和间隙水, 间隙水 $\mathrm{As}$ 浓度显著高于 地表水和上覆水; 地积累指数法和潜在生态危害指数法评价结果表明, 沉积物中重金属污染程度表现为 $\mathrm{Cd}>\mathrm{Pb}>\mathrm{As}, \mathrm{Cd}$ 污 染最严重, 达到“轻度一偏重度”污染程度, “中等一极强”生态危害级别, As 为清洁水平, 不同采样区重金属污染程度表现 为生活水产养殖区>纳污区>淀边缘区; 沉水植物重金属富集能力表现为金鱼藻 (Ceratophyllum demersum L.) > 薄草 (Potamogeton crispus L. ) 和穗状狐尾藻 (Myriophyllum spicatum L. ) >篦齿眼子菜 (Potamogeton pectinatus L.). 植物体内重金属含量 与体内氮、磷含量呈显著正相关,氮、磷营养盐影响沉水植物对重金属的富集.

关键词: 白洋淀;重金属;水体污染;沉水植物; 地积累指数法;生态危害指数法

\section{Distribution characteristics of heavy metals in sediment-submerged macrophyte-water systems of Lake Baiyangdian}

XUE Peiying $^{1}$, ZHAO Quanli $^{2}$, WANG Yaqiong ${ }^{1}$, GENG Liping ${ }^{1}$, CHEN Miaomiao ${ }^{3}$, WANG Xiaomei ${ }^{1}$ \& WANG Dianwu ${ }^{1}$

(1: College of Resources and Environmental Sciences, Hebei Agricultural University / Key Laboratory for Farm Land Eco-environment, Baoding 071000 , P.R.China)

(2: Farm of Teaching and Experimentation, Hebei Agricultural University, Baoding 071000, P.R.China)

(3: Institute of Science and Technology of Hebei Agricultural University, Baoding 071000, P.R.China)

Abstract: Concentrations of cadmium ( $\mathrm{Cd}$ ), lead $(\mathrm{Pb})$ and arsenic ( $\mathrm{As}$ ) in submerged macrophytes, the corresponding sediments and water ( surface water, pore water and overlying water) of Lake Baiyangdian have been determined to investigate the pollution and distribution characteristics of heavy metals in sediment-submerged macrophyte-water system and heavy metals accumulation ability of submerged macrophytes. The results showed that $\mathrm{Cd}, \mathrm{Pb}$ and $\mathrm{As}$ concentrations in surface water meet the standard of Class I of Environment Quality Standards for surface water ( GB 3838-2002), and no significant difference was observed in heavy metals concentrations between different regions. $\mathrm{Pb}$ concentrations in overlying water is greater than that in surface and pore water, while As concentrations in pore water is significantly higher than that in surface and overlying water. In addition, results of geo-accumulation index $\left(I_{\text {geo }}\right)$ and potential ecological risk index $(R I)$ showed that, heavy metals pollution in sediment in the pattern $\mathrm{Cd}>\mathrm{Pb}>\mathrm{As}$, with $\mathrm{Cd}$ coming up to slight to partial severe pollution and media to extremely strong ecological risk while As is still clean. Further, heavy metals contamination in sediment of different areas decreased in the order of Living and aquaculture area $>$ Sewage residence area $>$ Fringe area. Among the samples of submerged macrophytes the concentration of heavy metals were decreased in the order of Ceratophyllum demersum>Potamogeton crispus, Myriophyllum spicatum>Potamogeton pecinatus. It is worth noting that heavy metals concentrations in submerged macrophyte display obvious positive correlations with nitrogen and phosphorus con-

* 国家自然科学基金项目(21407042)、河北省自然科学基金项目( D2015204109)和河北省普通高等学校青年拔尖人 才项目 (BJ2014033) 联合资助. 2017-11-06 收稿; 2018-02-27 收修改稿. 薛培英 (1982 ), 女, 博士, 讲师; E-mail: pyxue0812@163.com. 
centrations in plants, which means that nitrogen and phosphorus may enhance heavy metals accumulation of submerged plants.

Keywords: Lake Baiyangdian; heavy metals; water pollution; submerged macrophyte; geo-accumulation index; potential ecological risk index

白洋淀位于大清河水系中部, 是华北地区最大的草型淡水湖泊. 在拦蓄洪水、灌溉生产、航运渔业和调 节气候等方面发挥巨大作用, 被誉为 “华北之肾”. 然而素有 “九河下梢”之称的白洋淀, 常年性人淀河流仅 剩下府河, 而府河主要接纳来自保定市的生活和工业污水, 每年有 $10^{5} \mathrm{~m}^{3}$ 污水和处理废水流人白洋淀 ${ }^{[1-2]}$, 此 外唐河污水库储存的工业废水每年冬季也进人白洋淀 ${ }^{[3]}$. 由于人淀水量的减少, 人淀污水的增多, 农业面源 污染的加剧, 加之淀区养殖业和旅游业的迅速发展 ${ }^{[4]}$, 自 $1970 \mathrm{~s}$ 以后, 白洋淀的水质逐渐恶化 ${ }^{[5-10]}$. 其中重金 属由于具有较强的毒性和持久性, 其污染问题逐渐受到人们重视. 研究表明, 白洋淀水中 $\mathrm{As} 、 \mathrm{~Pb} 、 \mathrm{Cd}$ 的浓度 数量级接近国家渔业水质标准 ${ }^{[11]}$; Chen 等 ${ }^{[12]}$ 研究显示白洋淀鱼体内富集的 $\mathrm{Hg}$ 和 As 含量超过美国环境保 护署 (USEPA) 标准. 水中的重金属可通过吸附、沉降等作用富集在沉积物, 使之成为水体系统重要的污染物 蓄积库 ${ }^{[13]}$. 研究表明白洋淀沉积物已经存在不同程度重金属污染, $\mathrm{Cd} 、 \mathrm{~Pb}$ 分别达到了极强和轻微一中度生 态危害, 极强和中度污染程度 ${ }^{[14]}$, 府河人口处沉积物 $\mathrm{Pb} 、 \mathrm{Zn}$ 达到中度污染 ${ }^{[15]}$. 由于沉积物中重金属在外界 条件改变 (水体扰动、水的氧化还原条件等) 时可以通过形态改变、浓度扩散、界面特性改变、释放、溶解等作 用由间隙水进人上覆水中进而影响水环境质量 ${ }^{[13,16]}$, 因此对沉积物和水相 (地表水一上覆水一间隙水) 中重 金属分布特征研究有助于揭示重金属在整个水体系统的迁移转化规律. 然而目前对白洋淀重金属污染状况 研究大多针对某一区域或单一系统 (水或沉积物 $)^{[17]}$, 并且由于白洋淀淀区由大小不等 100 多个淀泊组成, 不同淀区具有不同的功能 (如生活、旅游和水产养殖等), 其重金属来源及污染状况也不同 ${ }^{[18]}$, 因此, 有必要 对白洋淀不同功能淀区水体系统重金属的分布和污染状况进行研究.

沉水植物作为淡水湖泊生态系统中重要的大型水生植物, 具有生物量大、繁殖能力强和分布广泛等特 点, 此外由于其整株沉在水底, 地上部和根系可以分别从水和沉积物中吸收营养物质和重金属, 并可通过抑 制沉积物再悬浮等途径有效地去除水中的重金属, 修复水体污染 ${ }^{[19-22]}$. 同时由于沉水植物同时处于沉积物 和水两相之间, 植物体对重金属的迁移富集和释放对其在整个水生系统中的生物地球化学循环起重要作 用 ${ }^{[23]}$. 然而目前沉水植物存在体系下, 白洋淀水体重金属污染状况尚不清楚,并且缺乏不同功能淀区的对 比研究, 因此, 本文基于沉水植物不同生长季, 分别于 2015 年 4 月和 9 月对白洋淀不同功能淀区 (西部纳污 区、中部生活水产养殖区和淀边缘区) 10 个采样点优势沉水植物及其对应的水 (地表水、间隙水和上覆水) 和沉积物中重金属 $(\mathrm{Cd} 、 \mathrm{~Pb} 、 \mathrm{As})$ 含量进行测定, 以期明确白洋淀沉积物一沉水植物一水系统中重金属污染和 分布状况, 以及沉水植物对重金属的富集能力, 为沉水植物应用于白洋淀污染水体的生态治理提供理论 依据.

\section{1 材料与方法}

\section{1 样品采集与制备}

在白洋淀区 ( $38^{\circ} 45^{\prime} 37^{\prime \prime} \sim 38^{\circ} 59^{\prime} 22^{\prime \prime} \mathrm{N}, 115^{\circ} 45^{\prime} 45^{\prime \prime} \sim 116^{\circ} 06^{\prime} 57^{\prime \prime} \mathrm{E}$ ) 内布设 10 个有代表性的采样点 (图 1), 其中纳污区 ( A 区) 3 个 ( S1 为府河影响带 ( A2), S2、S3 均为唐河影响带 ( A1), 沉水植物覆盖度较低)、生活 水产养殖区 (B 区) 4 个 ( S4 S6 为生活水产养殖区 (B1), S7 为生活旅游区 (B2), 沉水植物覆盖度较高)、淀 边缘区 (C 区) 3 个 (S8 S10, 沉水植物覆盖度最高), 于 2015 年 4 月和 9 月采集表层沉积物、当季优势沉水 植物地上部和水样 (地表水、上覆水和间隙水), 每个样点采集 3 个样品作为重复. 采集的沉水植物样品主要 包括淔草 (Potamogeton crispus L.) ( 4 月份采集, 冬、春季生长型沉水植物) 以及金鱼藻 (Ceratophyllum demersum L.)、篦齿眼子菜 (Potamogeton pectinatus L.) 和穗状狐尾藻 (Myriophyllum spicatum L.) (均于 9 月份 采集, 夏、秋季生长型沉水植物), 将植物用超纯水清洗干净后于 $70^{\circ} \mathrm{C}$ 烘干至恒重, 粉碎; 用有机玻璃采水器 采集地表水 (水面下 $20 \mathrm{~cm}$ ) 和上覆水 (水和底泥交界面), 酸化至 $\mathrm{pH}<2$ 后过 $0.45 \mu \mathrm{m}$ 滤膜, 于 $4^{\circ} \mathrm{C}$ 保存. 采 用底泥抓斗器采集 $0 \sim 10 \mathrm{~cm}$ 沉积物, 一部分自然风干去杂过 100 目篮测定重金属含量, 另一部分置于聚乙 烯离心管中, 4000 转 $/ \mathrm{min}$ 离心 $30 \mathrm{~min}$, 上清液过 $0.45 \mu \mathrm{m}$ 滤膜后加硝酸酸化, 于 $4^{\circ} \mathrm{C}$ 保存待测, 为间隙水. 


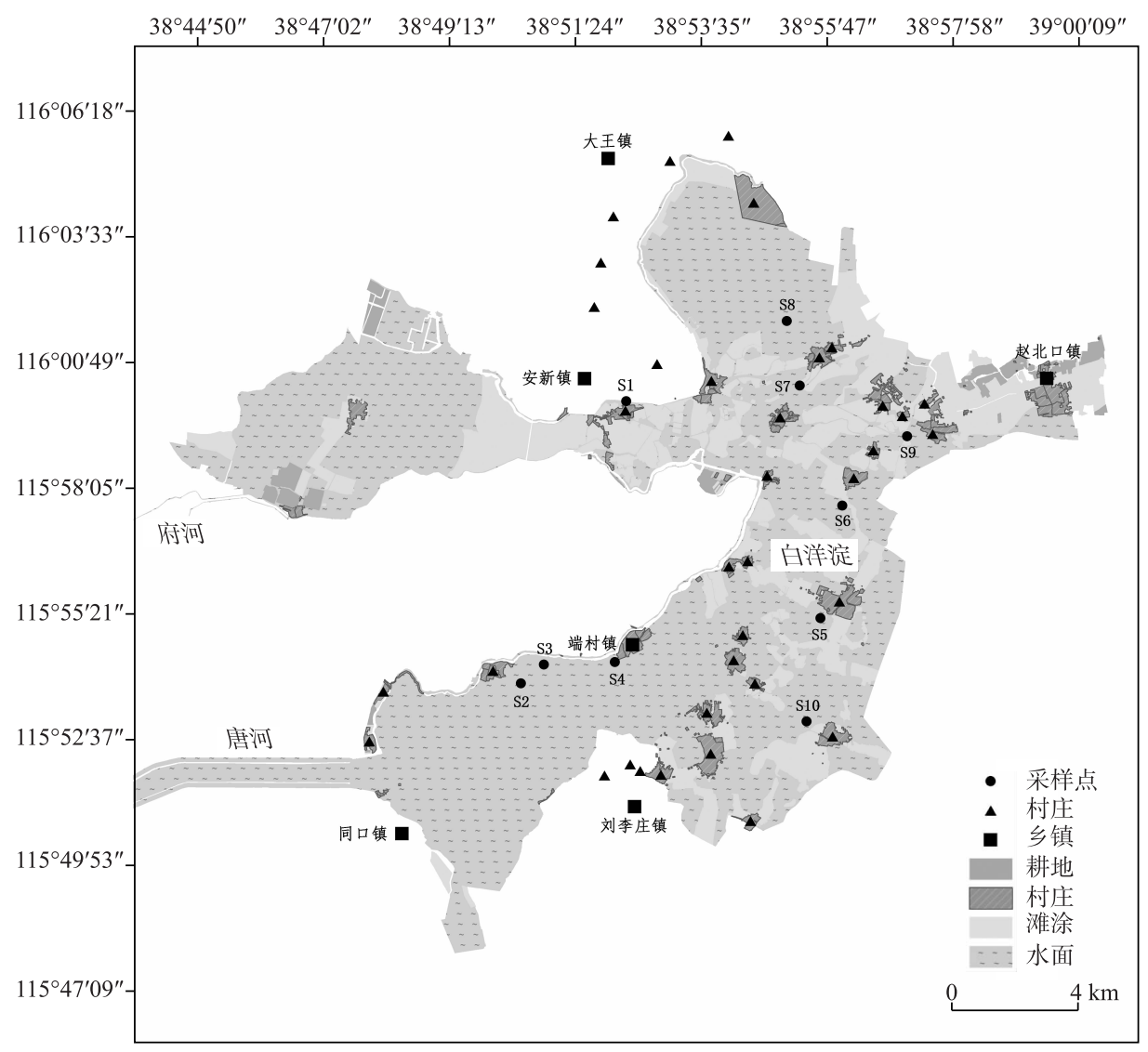

图 1 白洋淀采样点分布

Fig.1 Distribution of sampling sites in Lake Baiyangdian

\section{2 测定项目与方法}

土壤中 $\mathrm{Cd} 、 \mathrm{~Pb} 、 \mathrm{As}$ 全量采用四酸消解法 (GB/T 17141-1997) 进行消解,有效态 $\mathrm{Cd} 、 \mathrm{~Pb}$ 含量采用 DTPA 提取 ( GB/T 23739-2009), 有效态 $\mathrm{As}$ 含量采用 $\mathrm{NH}_{4} \mathrm{H}_{2} \mathrm{PO}_{4}$ 浸提法 ${ }^{[24]} \mathrm{Cd} 、 \mathrm{~Pb}$ 和 $\mathrm{As}$ 含量采用 ICP-MS (Agilent7500a) 和原子苂光 (AFS2202E) 进行测定, 以国家一级标准物质 (土壤: GBW07451、GBW07452 和 GBW07457; 植物: GBW07604) 进行准确度和精密度控制, 回收率为 80\% 90\%. 按比例随机检查和异常点抽 查进行样品分析质量监控, 以重复采样、重复分析来评定采样和分析误差.

\section{3 数据处理及评价方法}

采用 SPSS 17.0 软件进行方差分析和相关性分析, 用 Excel 2003 软件进行数据处理与制图. 白洋淀沉积 物重金属污染评价采用地累积指数法和潜在生态危害指数法.

1.3.1 地累积指数法 地累积指数法 $\left(I_{\mathrm{geo}}\right)$ 最早是由德国科学家 Müller ${ }^{[25]}$ 提出的用于研究沉积物中重金属污 染程度的指标. 其计算公式为:

$$
I_{\text {geo }}=\log _{2}\left(\frac{C_{i}}{k B_{i}}\right)
$$

式中, $I_{g e o}$ 为地累积指数, $C_{i}$ 为样品中第 $i$ 种元素的实际测量值 $(\mathrm{mg} / \mathrm{kg}), k$ 为修正指数,一般 $k=1.5 ; B_{i}$ 为第 $i$ 种元素的地球化学背景值 $(\mathrm{mg} / \mathrm{kg})$, 本文选取河北土壤元素背景值 ${ }^{[26]}, \mathrm{Cd} 、 \mathrm{~Pb}$ 和 $\mathrm{As}$ 含量分别为 $0.094 、 21.5$ 和 $13.6 \mathrm{mg} / \mathrm{kg}$. 地累积指数与重金属污染程度如表 1 所示.

1.3.2 生态风险评价指数法 Hakanson 潜在生态危害指数法是由 Hakanson ${ }^{[27]}$ 于 1980 年创立的从沉积学原 
表 1 地累积指数与污染级别 Tab.1 $I_{\text {geo }}$ and pollution levels

\begin{tabular}{ccc}
\hline 级数 & $I_{\text {geo }}$ 值 & 污染级别 \\
\hline 0 & $<0$ & 清洁 \\
1 & $0 \sim 1$ & 轻度污染 \\
2 & $1 \sim 2$ & 偏中度污染 \\
3 & $2 \sim 3$ & 中度污染 \\
4 & $3 \sim 4$ & 偏重度污染 \\
5 & $4 \sim 5$ & 重度污染 \\
6 & $\geqslant 5$ & 极重污染 \\
\hline
\end{tabular}

划分标准见表 2.
理评价重金属生态危害的方法. 潜在生态危害指数涉及单项污染指 数、重金属毒性响应系数以及潜在生态危害单项指数,计算公式 如下:

$$
\begin{gathered}
R I=\sum_{i}^{m} E_{r}^{i} \\
E_{r}^{i}=\sum_{i}^{m} T_{r}^{i} \cdot \frac{C_{i}}{C_{\mathrm{f}}}
\end{gathered}
$$

式中, $C_{i}$ 为某一重金属元素实际测量值 $(\mathrm{mg} / \mathrm{kg}), C_{\mathrm{f}}$ 为某一重金属元 素的标准值 $(\mathrm{mg} / \mathrm{kg}), T_{r}^{i}$ 为第 $i$ 种重金属的毒性系数 $(\mathrm{Cd} 、 \mathrm{~Pb}$ 和 $\mathrm{As}$ 毒性系数分别为 $30 、 5$ 和 10), $E_{r}^{i}$ 为第 $i$ 种重金属的潜在生态危害系 数, $R I$ 为多种重金属元素的综合潜在生态危害指数. 生态危害程度

表 2 生态危害程度划分标准

Tab.2 Degrees of potential ecological risk corresponding to the values $E_{r}^{i}$ and $R I$

\begin{tabular}{cccccc}
\hline 生态风险 & \multicolumn{5}{c}{ 生态危害程度 } \\
\cline { 2 - 5 } 评价指数 & 轻微 & 中等 & 强 & 很强 & 极强 \\
\hline$E_{r}^{i}$ & $<40$ & $40 \sim 80$ & $80 \sim 160$ & $160 \sim 320$ & $\geqslant 320$ \\
$R I$ & $<150$ & $150 \sim 300$ & $300 \sim 600$ & $\geqslant 600$ & \\
\hline
\end{tabular}

\section{2 结果与讨论}

\section{1 地表水一上覆水一间隙水中重金属浓度变化及分布特征}

白洋淀地表水、上覆水和间隙水中 3 种重金属浓度如图 2 所示. 对于地表水而言, $\mathrm{Cd} 、 \mathrm{~Pb} 、 \mathrm{As}$ 平均浓度 均达到《地表水环境质量标准 (GB 3838-2002)》I 类水质要求, 其中 $\mathrm{As}$ 平均浓度高于 $\mathrm{Pb}, \mathrm{Cd}$ 未检出. 以往 研究也同样表明, 尽管 1990s 后白洋淀水质逐渐恶化, 在 III IV 类之间, 一些淀区如南刘庄水质达劣 V 类 ${ }^{[10,28-29]}$, 但主要表现为氮磷营养超标, 重金属浓度均不超过地表水标准限值. 不同区域地表水 $\mathrm{Pb}$ 和 $\mathrm{As}$ 浓 度差异均不显著 $(P>0.05)$. 不同月份相比, 地表水 $\mathrm{Pb}$ 浓度差异不显著, 生活水产养殖区 ( B 区) 和淀边缘区 (C 区 $) 9$ 月份地表水 As 浓度比 4 月份高 $0.51 \sim 1.09$ 倍 $(P<0.05)$, 这可能是由于 9 月份降雨量较多加剧了农 业面源污染, 导致 $\mathrm{As}$ 输人增加 ${ }^{[30]}$, 而 $\mathrm{Pb}$ 可能受农业面源污染影响较小.

由于上覆水和间隙水中 $\mathrm{Cd}$ 浓度仅部分样点检出且浓度较低, 为 $0 \sim 0.3 \mu \mathrm{g} / \mathrm{L}$, 因此未分析 $\mathrm{Cd}$ 在不同水 相之间的分布规律, $\mathrm{Pb} 、 \mathrm{As}$ 在不同水相系统中的分布规律表现为: 无论是 4 月还是 9 月, 间隙水 $\mathrm{As}$ 浓度均显 著高于上覆水和地表水 $(P<0.05)$, 而上覆水和地表水中 As 浓度差异不显著 $(P>0.05)$, 相关关系结果表明, 地表水、上覆水和间隙水中 As 浓度之间均存在极显著正相关性 (表 3). 间隙水是沉积物与水界面污染物质 交换的重要介质, 研究表明间隙水中污染物浓度高于上覆水时可通过扩散作用进人上覆水中而成为湖泊水 体的重要污染源 ${ }^{[31-33]}$, 可见间隙水中 $\mathrm{As}$ 的释放是白洋淀水中 $\mathrm{As}$ 的重要来源; 而水中 $\mathrm{Pb}$ 浓度的分布则表现 为上覆水显著高于地表水和间隙水 $(P<0.05)$, 地表水和间隙水中 $\mathrm{Pb}$ 浓度差异不显著 $(P>0.05)$, 并且不同 水相中 $\mathrm{Pb}$ 浓度也不存在显著相关关系 $(P>0.05)$ (表 3$)$. 时春景等 ${ }^{[34]}$ 对永定河以及田林锋等 ${ }^{[35]}$ 对贵州红枫 湖的研究同样表明, 重金属在上覆水和间隙水中相关性很小, 这是由于水体系统污染物质迁移不仅受到自 身浓度的影响, 还受其他环境因素影响 (如 $\mathrm{pH}$ 值、有机物和微生物等), 其中悬浮物浓度是影响上覆水污染 物浓度的重要因素 ${ }^{[31]}$, 底泥表层细颗粒物会随水流扰动而增多 ${ }^{[36]}$. 本研究中, 纳污区由于沉水植物覆盖度 低, 而且作为人淀河流汇人处水流较强, 因此底泥的扰动较多, 促进了底泥中 $\mathrm{Pb}$ 的释放, 导致该区域上覆水 中 $\mathrm{Pb}$ 浓度显著高于其他采样区 $(P<0.05)$. 此外地表水中 $\mathrm{Pb}$ 浓度可能受外源污染影响较大, 一方面, 研究 表明大气沉降是环境中 $\mathrm{Pb}$ 的主要来源 ${ }^{[37-38]}$, 另一方面白洋淀作为著名旅游景区, 每年接待游客 85 万, 柴油 
机动船为主要运输工具 ${ }^{[39]}$, 其尾气排放也会成为水中 $\mathrm{Pb}$ 的污染源.

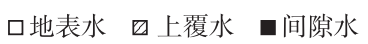
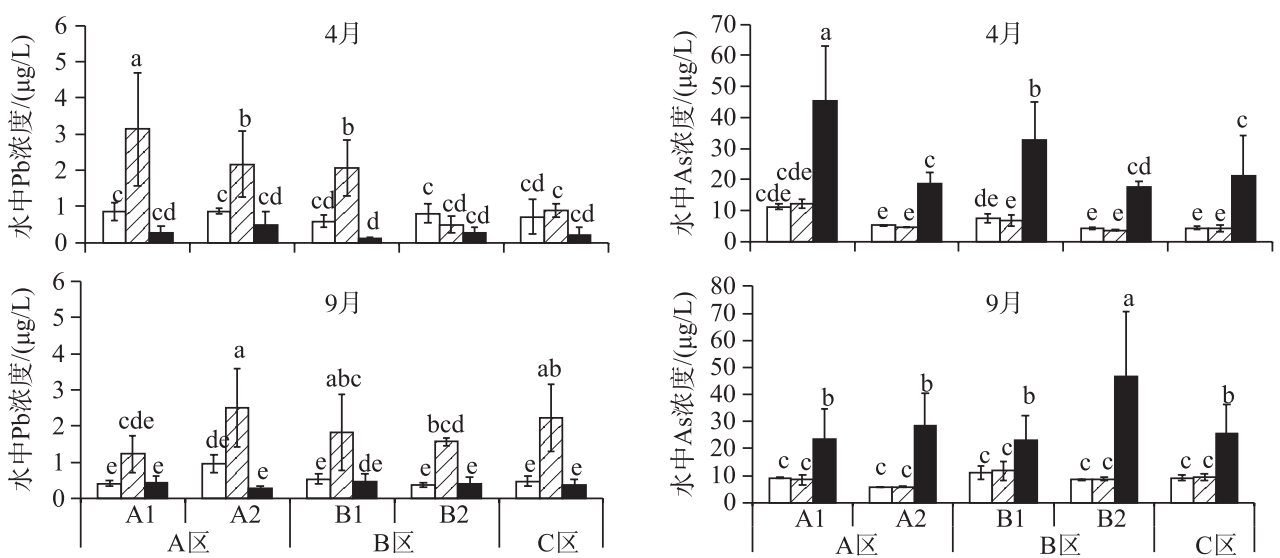

采样区

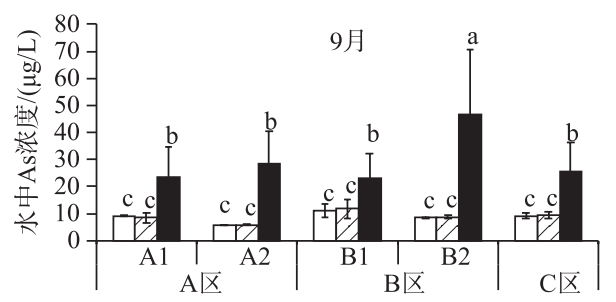

采样区

图 2 不同采样区地表水一上覆水一间隙水中 $\mathrm{Pb}$ 和 $\mathrm{As}$ 浓度 (不同字母表示水体重金属浓度之间差异显著 $(P<0.05)$ )

Fig.2 Concentration of $\mathrm{Pb}$ and $\mathrm{As}$ in surface water, overlying water and pore water of different sampling sites (Different letters indicate significant difference between heavy metal concentrations in water)

表 3 地表水一上覆水一间隙水中重金属含量之间的相关性

Tab.3 Pearson's correlation between heavy metals contents in surface water, overlying water and pore water

\begin{tabular}{|c|c|c|c|c|c|c|}
\hline & 地表水 $\mathrm{Pb}$ & 地表水 As & 间隙水 $\mathrm{Pb}$ & 间隙水 As & 上覆水 $\mathrm{Pb}$ & 上覆水 $\mathrm{As}$ \\
\hline 地表水 $\mathrm{Pb}$ & 1 & & & & & \\
\hline 地表水 As & 0.020 & 1 & & & & \\
\hline 间隙水 $\mathrm{Pb}$ & -0.065 & $0.786^{* *}$ & 1 & & & \\
\hline 间隙水 As & 0.028 & $0.954^{\text {** }}$ & $0.770^{* *}$ & 1 & & \\
\hline 上覆水 $\mathrm{Pb}$ & 0.002 & 0.021 & 0.064 & 0.085 & 1 & \\
\hline 上覆水 $\mathrm{As}$ & 0.367 & $0.657^{* * *}$ & $0.469^{* *}$ & $0.584^{* *}$ & -0.091 & 1 \\
\hline
\end{tabular}

** 表示在 0.01 水平 $($ 双侧 $)$ 上显著相关; * 表示在 0.05 水平 $($ 双侧 $)$ 上显著相关. 下同.

\section{2 沉积物中重金属含量变化及分布特征}

沉积物是污染物质的重要蓄积库, 当外界条件改变时会成为湖泊污染的重要来源, 因此研究沉积物中 重金属含量及其分布对于明确白洋淀水体重金属污染状况至关重要. 白洋淀不同采样区沉积物中重金属全 量如图 3 所示. 沉积物中重金属全量表现为 $\mathrm{Pb}>\mathrm{As}>\mathrm{Cd}, \mathrm{Pb} 、 \mathrm{As} 、 \mathrm{Cd}$ 全量分别为 $20.20 \sim 328 \mathrm{mg} / \mathrm{kg}$ (平均值为 $44.42 \mathrm{mg} / \mathrm{kg}$, 变异系数为 1.05 ) 、4.80 32.10 mg/ $\mathrm{kg}$ (平均值为 $10.98 \mathrm{mg} / \mathrm{kg}$, 变异系数为 0.44 ) 和 $0.15 \sim 3.06$ $\mathrm{mg} / \mathrm{kg}$ (平均值为 $0.42 \mathrm{mg} / \mathrm{kg}$, 变异系数为 0.97 ), $\mathrm{Pb} 、 \mathrm{As}$ 和 $\mathrm{Cd}$ 全量分别为河北省土壤背景值 ${ }^{[26]}$ 的 $0.94 \sim$ $15.62 、 0.35 \sim 2.36$ 和 1.60 32.55 倍, 除 As 含量与背景值相近外, 其他金属元素均表现出明显的累积效应, 其 中 $\mathrm{Cd}$ 超出背景值的倍数最大, 表明其在白洋淀底泥中累积最为严重. 此外 $\mathrm{Pb}$ 和 $\mathrm{Cd}$ 的变异系数均较高, 并 且这 2 种重金属全量之间存在极显著正相关关系, 而与 As 不存在显著相关关系 (数据未列出), 说明沉积物 $\mathrm{Cd} 、 \mathrm{~Pb}$ 具有相似的来源且受人为因素影响较大,而 $\mathrm{As}$ 含量则主要受母质影响.

无论在 4 月还是 9 月,沉积物中 $\mathrm{Cd} 、 \mathrm{~Pb}$ 全量均表现为生活旅游区 (B2) 最高, 分别比其他功能区高 1.22 5.37 和 0.09 6.07 倍, 其他采样区之间 $\mathrm{Cd} 、 \mathrm{~Pb}$ 全量差异均不显著 $(P>0.05)$; 沉积物中 $\mathrm{As}$ 全量表现为 纳污区府河影响带 (A2) 最低, 其他采样区之间差异均不显著 $(P>0.05)$. 不同月份相比, 沉积物 $\mathrm{Cd}$ 全量差异 
不显著, $\mathrm{Pb}$ 和 $\mathrm{As}$ 全量均表现为 4 月显著高于 9 月 $(P<0.05)$, 这可能与沉水植物衰亡后体内重金属向外释 放有关, 本研究表明, 夏、秋季生长型 (4 月衰亡) 沉水植物特别是金鱼藻对 $\mathrm{Pb}$ 和 $\mathrm{As}$ 的富集能力均高于冬、 春季沉水植物菹草,也因此建议适时收割沉水植物可减少重金属向水体的释放.
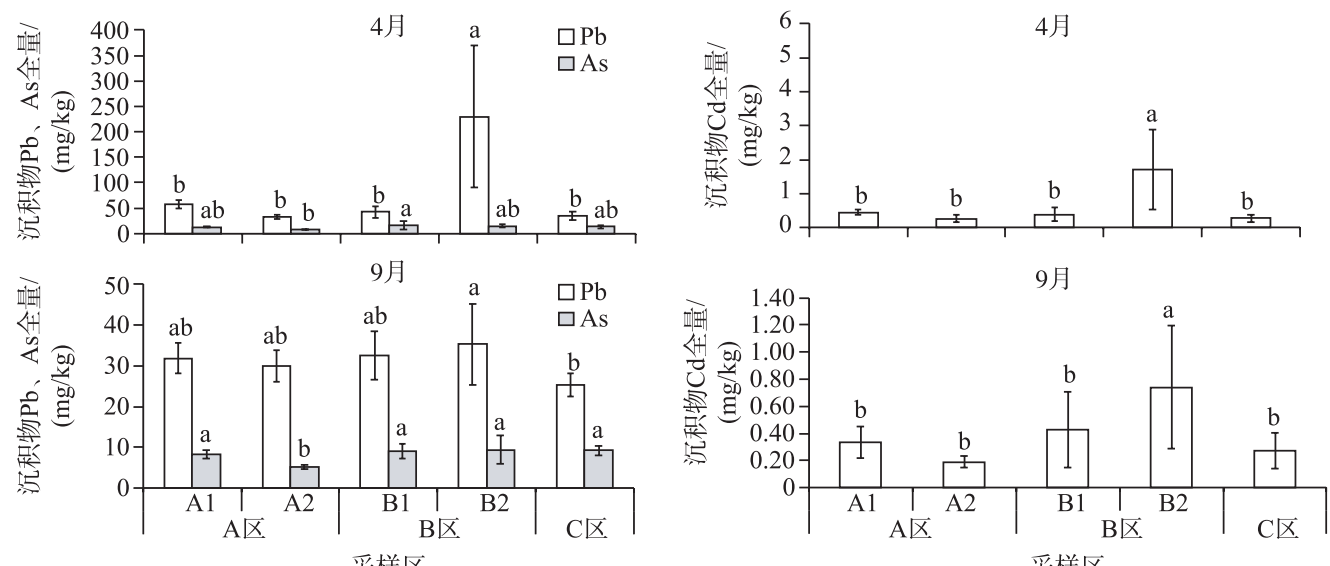

图 3 不同采样区沉积物中 $\mathrm{Cd} 、 \mathrm{~Pb} 、 \mathrm{As}$ 全量

(不同字母表示不同采样点沉积物同种重金属全量之间差异显著 $(P<0.05)$ )

Fig. 3 Contents of $\mathrm{Cd}, \mathrm{Pb}$ and $\mathrm{As}$ in sediment of different sampling sites

(Different letters indicate significant difference between heavy metal contents in sediment of different sampling sites)

沉积物中重金属的潜在危害程度不仅与重金属全量有关, 更重要的是取决于重金属的生物有效性,因 此对白洋淀底泥沉积物有效态 $\mathrm{Cd} 、 \mathrm{~Pb} 、 \mathrm{As}$ 含量进行分析, 结果如表 4 所示. 沉积物中有效态 $\mathrm{Cd} 、 \mathrm{~Pb} 、 \mathrm{As}$ 含量 同样表现为 $\mathrm{Pb}>\mathrm{As}>\mathrm{Cd}$. 虽然沉积物中 $\mathrm{Cd}$ 全量和有效态含量较低, 但是有效态占全量的比例最高, 为 $12.92 \% \sim 66.38 \%$, 特别是 $\mathrm{Cd}$ 全量最高的生活旅游区 ( B2), 其有效态 $\mathrm{Cd}$ 比例也显著高于其他采样区 $(P<$ $0.05)$, 其他采样区之间 $\mathrm{Cd}$ 有效态含量差异不显著; 虽然沉积物中 $\mathrm{Pb}$ 全量最高, 但有效态 $\mathrm{Pb}$ 含量占全量的 比例较低, 为 $5.50 \% \sim 27.17 \%, \mathrm{As}$ 的有效态含量占全量的比例最小, 为 $2.87 \% \sim 5.36 \%$. 不同功能区相比, 无 论 4 月份还是 9 月份,均表现为生活水产养殖区沉积物 $\mathrm{Cd} 、 \mathrm{~Pb}$ 和 $\mathrm{As}$ 有效态含量最高, 淀边缘区和纳污区 较低.

表 4 不同采样区沉积物重金属有效态含量状况 *

Tab.4 Contents of available heavy metals in the sediments of different sampling sites

\begin{tabular}{|c|c|c|c|c|c|c|c|c|}
\hline 时间 & 采样区 & & $\begin{array}{l}\text { 有效态 } \mathrm{Cd} / \\
(\mathrm{mg} / \mathrm{kg})\end{array}$ & $\begin{array}{c}\text { 占全量 } \\
\text { 的比例 } / \%\end{array}$ & $\begin{array}{c}\text { 有效态 } \mathrm{Pb} / \\
(\mathrm{mg} / \mathrm{kg})\end{array}$ & $\begin{array}{c}\text { 占全量 } \\
\text { 的比例/\% }\end{array}$ & $\begin{array}{c}\text { 有效态 As/ } \\
(\mathrm{mg} / \mathrm{kg})\end{array}$ & $\begin{array}{c}\text { 占全量 } \\
\text { 的比例 } / \%\end{array}$ \\
\hline \multirow[t]{5}{*}{4 月 } & A 区 & $\mathrm{A} 1$ & $0.08 \pm 0.06^{\mathrm{b}}$ & 12.92 & $3.06 \pm 2.22^{\text {be }}$ & 5.50 & $0.39 \pm 0.06^{\mathrm{bc}}$ & 3.12 \\
\hline & & A2 & $0.07 \pm 0.01^{\mathrm{b}}$ & 27.92 & $5.87 \pm 0.50^{\mathrm{bc}}$ & 17.41 & $0.22 \pm 0.02^{\mathrm{c}}$ & 3.09 \\
\hline & B 区 & B1 & $0.26 \pm 0.22^{\mathrm{b}}$ & 46.32 & $7.92 \pm 3.16^{\mathrm{b}}$ & 19.75 & $0.59 \pm 0.28^{\mathrm{ab}}$ & 3.78 \\
\hline & & B2 & $0.91 \pm 0.15^{\mathrm{a}}$ & 66.38 & $12.00 \pm 3.52^{\mathrm{a}}$ & 14.08 & $0.79 \pm 0.13^{\mathrm{a}}$ & 5.36 \\
\hline & C 区 & & $0.08 \pm 0.04^{b}$ & 27.50 & $2.91 \pm 1.09^{c}$ & 8.75 & $0.36 \pm 0.06^{\mathrm{bc}}$ & 2.96 \\
\hline \multirow[t]{5}{*}{9 月 } & A 区 & $\mathrm{A} 1$ & $0.10 \pm 0.04^{\mathrm{b}}$ & 31.29 & $5.20 \pm 1.85^{\mathrm{b}}$ & 16.05 & $0.31 \pm 0.05^{\mathrm{ab}}$ & 3.77 \\
\hline & & A2 & $0.05 \pm 0.01^{\mathrm{b}}$ & 22.84 & $3.47 \pm 0.31^{\mathrm{bc}}$ & 11.82 & $0.15 \pm 0.04^{b}$ & 2.87 \\
\hline & B 区 & B1 & $0.08 \pm 0.04^{\mathrm{b}}$ & 23.12 & $5.00 \pm 1.91^{\mathrm{b}}$ & 15.10 & $0.38 \pm 0.17^{\mathrm{a}}$ & 4.03 \\
\hline & & B2 & $0.66 \pm 0.23^{\mathrm{a}}$ & 31.34 & $13.50 \pm 0.42^{\mathrm{a}}$ & 27.17 & $0.36 \pm 0.14^{\mathrm{a}}$ & 3.91 \\
\hline & C 区 & & $0.07 \pm 0.05^{\mathrm{b}}$ & 24.63 & $2.47 \pm 1.27^{\mathrm{c}}$ & 9.71 & $0.31 \pm 0.09^{\mathrm{ab}}$ & 3.39 \\
\hline
\end{tabular}

* 不同字母表示同一月份不同区域同种重金属有效态含量之间差异显著 $(P<0.05)$. 


\section{3 沉积物重金属污染评价}

采用地累积指数法和潜在生态风险指数法对白洋淀沉积物重金属的污染水平及生态危害进行评价 (图 $4)$, 结果表明, 白洋淀沉积物中重金属污染程度表现为 $\mathrm{Cd}>\mathrm{Pb}>\mathrm{As}$. 其中 $\mathrm{Cd}$ 的 $I_{\mathrm{geo}}$ 值为 $0.43 \sim 3.61$, 为轻度到 偏重度污染; $\mathrm{Pb}$ 的 $I_{\mathrm{geo}}$ 值为 $-0.35 \sim 2.83$, 为清洁到中度污染; $\mathrm{As}$ 的 $I_{\mathrm{geo}}$ 值在各采样区均小于 0 , 为清洁水平. 无 论在 4 月还是 9 月, 沉积物 $\mathrm{Cd} 、 \mathrm{~Pb}$ 含量均在生活旅游区污染最为严重, 为轻度到偏重度污染, 淀边缘区和纳 污区府河影响带污染最轻, 为清洁到轻度污染水平.

白洋淀沉积物重金属的生态危害顺序同样表现为: $\mathrm{Cd}>\mathrm{Pb}>\mathrm{As}$. 其中 $\mathrm{Cd}$ 的潜在生态危害系数为 $60.64 \sim$ 547.87 , 达到中等一极强生态危害级别; 除 4 月份生活旅游区沉积物 $\mathrm{Pb}$ 含量达到中等生态危害级别, 沉积物 中 $\mathrm{Pb} 、 \mathrm{As}$ 生态危害系数均低于 40 , 为轻微生态危害级别. 综合潜在生态危害指数 $(R I)$ 整体表现为生活水产 养殖区>纳污区>淀边缘区, 为轻微一很强生态危害级别, 其中生活旅游区 (B2) 重金属危害程度最高, 4 月 $(R I=612.15)$ 和 9 月 $(R I=251.34)$ 分别达很强和中等生态危害级别.

总之, 评价结果表明白洋淀沉积物 $\mathrm{Cd}$ 污染程度最高, 并且有效态 Cd 含量占全量的百分比也最高, 可见 白洋淀沉积物中 $\mathrm{Cd}$ 污染问题应予以高度重视, 其次是 $\mathrm{Pb}$, 这与杨卓等 ${ }^{[14]}$ 的研究结果一致. 不同采样区相 比, 生活水产养殖区沉积物重金属污染程度最高, 这可能是由于该区域人类活动较为集中, 生活污水排泄 物、垃圾和粪便、鱼蟹饵料 ${ }^{[40]}$ 等直接或间接人淀,这些污染物质沉积到沉积物表层,造成重金属的累积,而且 该区域沉水植物覆盖度较高, 植物腐烂后也会成为水体污染物的重要来源 ${ }^{[41]}$. 因此白洋淀区内部污染源的 控制对整个水体污染的修复尤为重要. 此外纳污区作为承接污染物的主要区域,其重金属污染程度也相对 较高, 胡国成等 ${ }^{[18]}$ 研究表明白洋淀沉积物重金属污染与府河有相似污染源, 保定市生活污水、工业废水以及 沿岸冶炼企业排污可能是该地区重金属主要来源, Xu 等 ${ }^{[42]}$ 对白洋淀生态系统健康评价结果同样表明处于 淀边缘的西南、东南区生态健康状况最佳,其次为中、南部区, 最差的为西部纳污区.

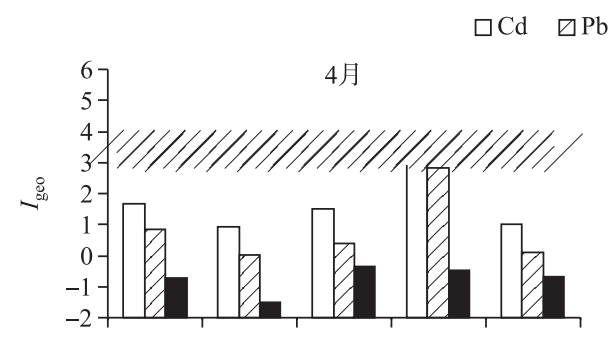

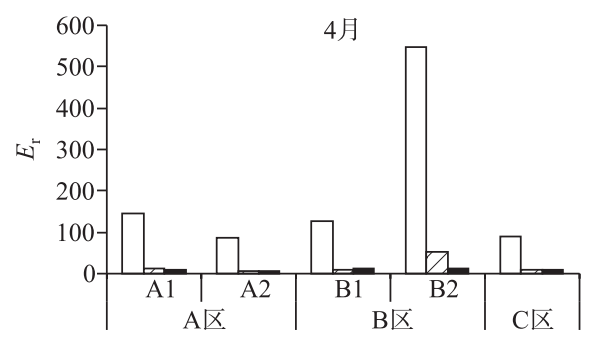

采样区
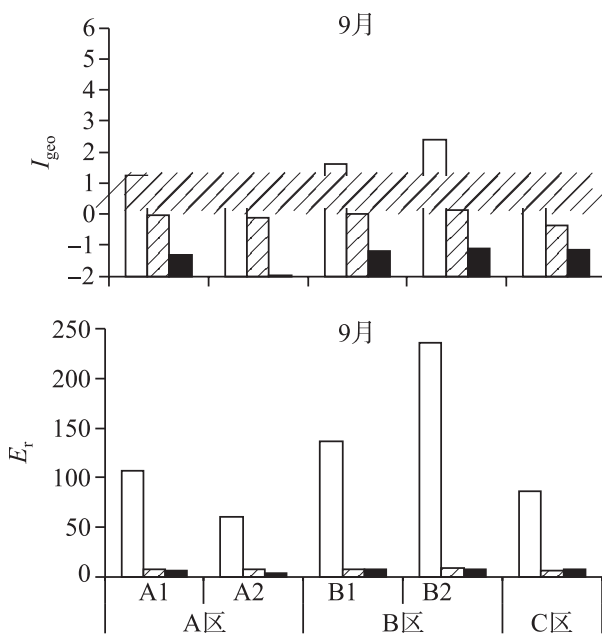

采样区

图 4 白洋淀沉积物中重金属地累积指数和潜在生态风险评价结果

Fig.4 $I_{\text {geo }}$ and potential ecological risk assessment results of heavy metals in the sediment of Lake Baiyangdian

\section{4 沉水植物重金属分布特征}

沉水植物作为水体生态系统中水和底质两大营养库之间的有机接合部, 其生长代谢对污染物的迁移释 放起重要作用. 沉水植物体内重金属含量见图 5 : 沉水植物对 3 种金属的富集能力均表现为 $\mathrm{As}>\mathrm{Pb}>\mathrm{Cd}$. 其 中金鱼藻对 $\mathrm{Cd} 、 \mathrm{~Pb} 、 \mathrm{As}$ 的富集能力均最强, 其次为薄草和穗状狐尾藻, 而眼子菜对 3 种金属富集能力最弱. Zhang 等 ${ }^{[43]}$ 对太湖 4 种沉水植物 As 含量调查研究也表明, 金鱼藻体内 As 富集量最高, 可达 $12.0 \mathrm{mg} / \mathrm{kg}$, 其 
次为穗状狐尾藻、黑藻 (Hydrilla verticillata)、眼子菜 (Potamogeton octandrus Poir.). Xue 等 ${ }^{[44]}$ 研究也表明金 鱼藻在 $10 \mu \mathrm{mol} / \mathrm{L} \mathrm{As}$ 溶液中暴露 4 天, 最大富集量 $>800 \mathrm{mg} / \mathrm{kg}$, 其富集能力高于其他沉水植物 (如黑藻和狐 尾藻等), 这可能与金鱼藻无根缺少由根向地上部转运的阻碍有关. 此外, 冬、春季生长型沉水植物菹草对水 体 $\mathrm{Cd} 、 \mathrm{~Pb}$ 富集能力也较高, 崔晨等 ${ }^{[45]}$ 研究同样表明, 菹草对微污水中重金属镉、锰、镍具有超积累的富集作 用, 可见菹草对于冬、春季水体重金属污染修复起重要作用. 不同采样区相比,纳污区府河影响带 (A2) 植物 体内 $\mathrm{Cd} 、 \mathrm{~Pb}$ 含量较高; 生活水产养殖区 ( B 区) 植物体内 $\mathrm{Pb} 、 \mathrm{As}$ 含量较高.
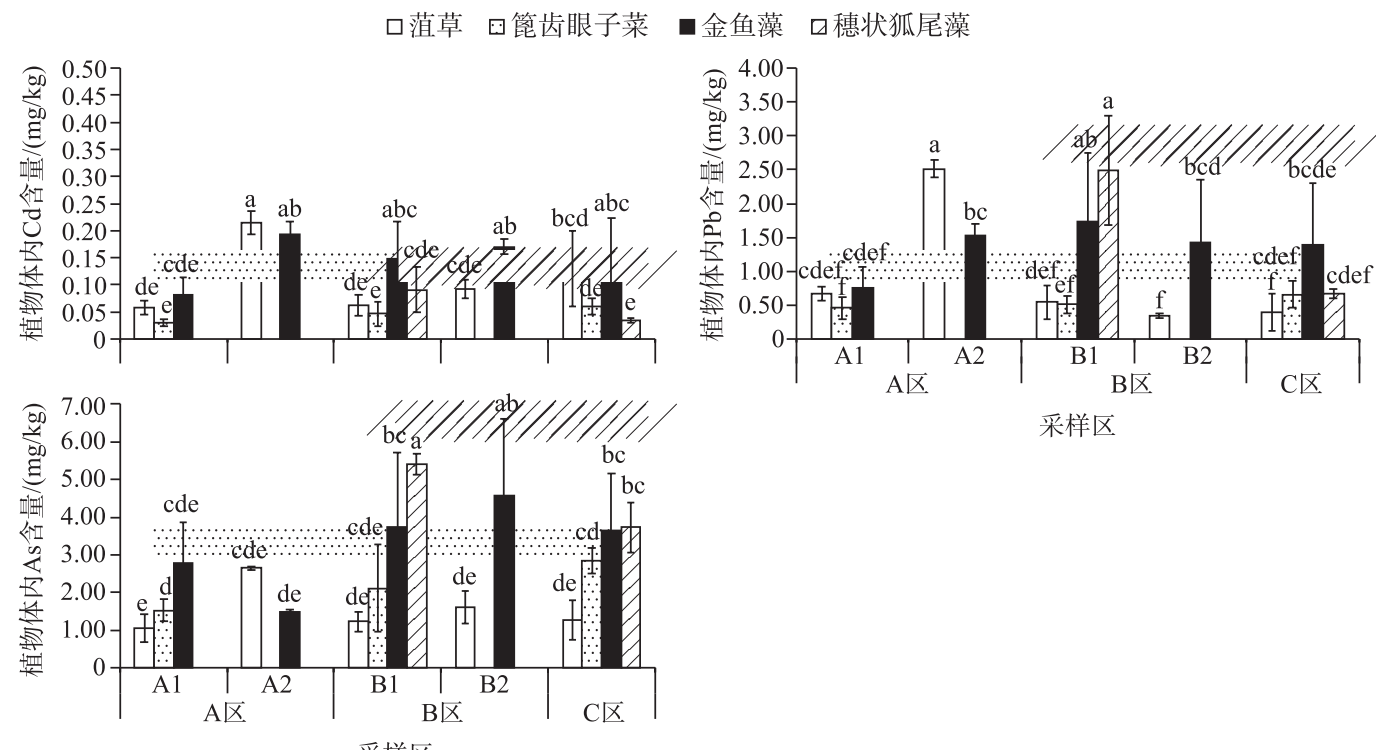

采样区

采样区

图 5 不同采样区沉水植物体内 $\mathrm{Cd} 、 \mathrm{~Pb}$ 和 $\mathrm{As}$ 含量

Fig.5 Contents of $\mathrm{Cd}, \mathrm{Pb}$ and As in submerged macrophytes of different sampling sites

\section{5 沉水植物与水体中重金属和氮、磷含量相关性}

2.5 .1 沉水植物与水体中重金属全量的相关性 沉水植物菹草重金属全量与水中重金属浓度之间的相关性 结果见表 5. 蕰草和篦齿眼子菜体内 $\mathrm{Cd} 、 \mathrm{~Pb} 、 \mathrm{As}$ 含量之间均存在极显著正相关关系 $(P<0.01)$, 说明 3 种金属 的吸收具有同源性; 菹草体内 $\mathrm{Pb}$ 含量与地表水、间隙水和上覆水中 $\mathrm{Pb}$ 浓度均存在显著或极显著正相关关 系, 但是 As 含量与水中 As 浓度之间不存在相关关系, 菹草体内 3 种重金属含量与沉积物中重金属全量和 有效态含量之间也均不存在相关关系 (数据未列出), 表明菹草体内富集的 $\mathrm{Pb}$ 可能主要通过地上部自水相 吸收而非通过根系自沉积相吸收. 崔晨等 ${ }^{[45]}$ 研究也表明菹草地上部对重金属的富集能力高于根系, 且新叶 富集能力高于老叶. 金鱼藻体内重金属除 $\mathrm{Cd}$ 和 $\mathrm{As}$ 之外也存在极显著正相关关系, 狐尾藻体内只有 $\mathrm{Cd} 、 \mathrm{~Pb}$ 含量存在显著正相关关系; 与菹草不同的是这 2 种沉水植物体内重金属含量与水和沉积物中重金属含量均 不存在显著相关关系 (结果未列出).

表 5 白洋淀沉水植物与水中重金属含量的相关性

Tab.5 Pearson's correlation between heavy metals concentrations in submerged macrophytes and waters of Lake Baiyangdian

\begin{tabular}{rlllllllll}
\hline 相关性 & 菹草 $\mathrm{Cd}$ & 萁草 $\mathrm{Pb}$ & 菹草 $\mathrm{As}$ & 地表水 $\mathrm{Pb}$ & 地表水 $\mathrm{As}$ & 间隙水 $\mathrm{Pb}$ & 间隙水 $\mathrm{As}$ & 上覆水 $\mathrm{Pb}$ & 上覆水 $\mathrm{As}$ \\
\hline 埧草 $\mathrm{Cd}$ & 1 & $0.471^{* *}$ & $0.522^{* *}$ & 0.223 & $-0.554^{* *}$ & -0.257 & $-0.474^{*}$ & 0.374 & -0.353 \\
蕰草 $\mathrm{Pb}$ & $0.471^{* *}$ & 1 & $0.727^{* *}$ & $0.382^{*}$ & 0.172 & $0.433^{*}$ & 0.140 & $0.577^{* *}$ & 0.174 \\
菹草 $\mathrm{As}$ & $0.522^{* *}$ & $0.727^{* *}$ & 1 & 0.358 & -0.274 & -0.065 & -0.313 & $0.504^{* *}$ & 0.058 \\
\hline
\end{tabular}


2.5.2 沉水植物体内重金属与氮、磷含量的相关性 本研究小组前期调查了该区域沉水植物、水体和 沉积物中氮、磷总含量 ${ }^{[28]}$. 将沉水植物体内重金 属含量和植物体内以及水体氮、磷含量做相关性, 结果见表 6 和表 7.

蕰草体内重金属含量与植物体 TN 和 TP 含 量以及水体 TN 和 TP 浓度之间均存在极显著正 相关关系 (植物体内 $\mathrm{Cd}$ 含量与水体 TP 浓度除 外)，但是植物体内重金属含量与沉积物 TN 和 TP 含量之间均不存在相关关系 (植物体内 $\mathrm{Pb}$ 含量 与沉积物 TP 含量除外); 由于夏、秋季沉水植物 中篦齿眼子菜和穗状狐尾藻只采集了部分样点, 因此只做了金鱼藻体内重金属与环境中氮、磷相 关性,结果表明,体内 $\mathrm{Cd} 、 \mathrm{~Pb}$ 含量与植物体内 $\mathrm{TN}$ 和 TP 含量存在显著或极显著正相关,但是体内金 属含量与水和沉积物中 TN 和 TP 含量均不存在 显著相关关系. 由此可见沉水植物对重金属的吸 收受水中氮、磷富营养的影响, 植物对氮、磷营养 的吸收可能会促进沉水植物对重金属的吸收富 集. 这是由于一方面,氮、磷营养盐可以通过促进 植物生长来提高对重金属等污染物质的吸收富 集,另一方面,也可以通过影响重金属离子在植物
表 6 菹草体内重金属含量与水体和 沉积物中氮、磷含量的相关性

Tab.6 Pearson's correlation between heavy metal contents in $P$. crispus and nitrogen and

phosphorus contents in the water and sediment

\begin{tabular}{|c|c|c|c|c|c|c|}
\hline & $\begin{array}{c}\text { 菹草 } \\
\text { TN }\end{array}$ & $\begin{array}{c}\text { 菹草 } \\
\text { TP }\end{array}$ & $\begin{array}{l}\text { 水体 } \\
\mathrm{TN}\end{array}$ & $\begin{array}{l}\text { 水体 } \\
\mathrm{TP}\end{array}$ & $\begin{array}{c}\text { 沉积物 } \\
\text { TN }\end{array}$ & $\begin{array}{c}\text { 沉积物 } \\
\text { TP }\end{array}$ \\
\hline 菹草 Cd & $0.774^{* *}$ & $0.689^{* * *}$ & $0.509^{* *}$ & 0.305 & -0.126 & 0.212 \\
\hline 菹草 Pb & $0.533^{* *}$ & $0.562^{* *}$ & $0.914^{* *}$ & $0.862 *$ & $*-0.208$ & 0.360 * \\
\hline 菹草 As & $0.474^{* *}$ & $0.480^{\text {*** }}$ & $0.675^{* *}$ & 0.464 * & 0.027 & 0.311 \\
\hline
\end{tabular}

表 7 金鱼藻体内重金属含量与 水体和沉积物中氮、磷含量的相关性

Tab.7 Pearson's correlation between heavy metal contents in $C$. demersum and nitrogen and phosphorus contents in the water and sediment

\begin{tabular}{ccccccc}
\hline & $\begin{array}{c}\text { 金鱼藻 } \\
\mathrm{TN}\end{array}$ & $\begin{array}{c}\text { 金鱼藻 } \\
\mathrm{TP}\end{array}$ & $\begin{array}{c}\text { 水体 } \\
\mathrm{TN}\end{array}$ & \multicolumn{2}{c}{ 水体 } & \multicolumn{2}{c}{ 沉积物 沉积物 } \\
$\mathrm{TP}$ & $\mathrm{TN}$ & $\mathrm{TP}$ \\
\hline 金鱼藻 $\mathrm{Cd}$ & $0.601^{* *}$ & $0.579^{* *}$ & -0.153 & 0.282 & -0.181 & -0.223 \\
金鱼藻 $\mathrm{Pb}$ & $0.438^{*}$ & $0.435^{*}$ & -0.132 & 0.138 & -0.279 & -0.185 \\
金鱼藻 $\mathrm{As}$ & -0.169 & -0.057 & -0.302 & -0.410 & -0.024 & -0.315 \\
\hline
\end{tabular}

体的存在形态来提高对重金属的耐性进而促进其吸收,如氮可通过合成植物蛋白质(如植物鳌合剂、金属颈 蛋白、脯氨酸等) 与重金属离子形成鳌合物缓解其毒害作用 ${ }^{[46]}$, 而磷可以与重金属离子形成复合物促进其 在细胞壁的结合 ${ }^{[47]}$. 此外也有研究表明硝态氮的加人可以提高水稻 OsIRT1 (铁转运蛋白) 的表达进而促进 根系对 $\mathrm{Cd}$ 的吸收 ${ }^{[48]}$. 总之, 湖泊水体富营养化已经成为我国乃至世界重要的环境问题, 氮、磷营养盐作为 主要影响因子, 对重金属在湖泊水体系统的迁移转化也起到重要影响, 因此进一步研究氮、磷营养盐对重金 属在沉积物一沉水植物一水体系统的迁移转化至关重要.

\section{3 结论}

1) 白洋淀 10 个采样区地表水 $\mathrm{Cd} 、 \mathrm{~Pb} 、 \mathrm{As}$ 浓度均符合我国地表水 I 类水质标准,不同采样区差异不显著. 上覆水 $\mathrm{Pb}$ 浓度显著高于地表水和间隙水,不同水相中 $\mathrm{Pb}$ 浓度无显著相关性, 而 $\mathrm{As}$ 表现为间隙水浓度显著 高于地表水和上覆水,间隙水为水中 As 的主要来源.

2) 地累积指数和潜在生态危害指数结果表明, 白洋淀沉积物受到一定程度的 $\mathrm{Cd}$ 和 $\mathrm{Pb}$ 污染, 其中 $\mathrm{Cd}$ 污 染程度最高, 为“轻度到偏重度”污染, “中等一极强”生态危害级别, As 尚清洁. 沉积物重金属污染程度表现 为生活水产养殖区>纳污区>淀边缘区, 主要受内源污染影响.

3) 4 种沉水植物中金鱼藻对 $\mathrm{Cd} 、 \mathrm{~Pb}$ 和 As 富集能力最强,其次是菹草和穗状狐尾藻,篦齿眼子菜富集能 力最低. 沉水植物体内重金属含量与氮、磷含量存在显著正相关关系, 氮、磷营养盐可促进植物对重金属的 富集.

\section{4 参考文献}

[ 1 ] Wei QW, Li HB, Liu LJ et al. The influences of pollutants distribution for the ecological water transfer based on the spatial differentiation in Baiyangdian Lake. Advanced Materials Research, 2012, 518-523 : 2912-2919.

[ 2 ] Qi Y, Wang Z, Pei Y. Evaluation of water quality and nitrogen removal bacteria community in Fuhe River, The 18th Bien- 
nial Conference of International Society for Ecological Modelling. Procedia Environmental Science, 2012, 13: 1809-1819.

[ 3 ] Yuan RQ, Song XF, Wang P et al. Impacts of percolation in Baiyangdian Lake on groundwater. Advances in Water Science, 2012, 23(6) : 751-756. [袁瑞强, 宋献方, 王鹏等. 白洋淀渗漏对周边地下水的影响. 水科学进展, 2012, 23(6): 751-756. ]

[ 4 ] Bian W, Wang LG, Zhang HZ et al. Study on phosphorus pollution load of aquaculture in Baiyangdian Lake. Advanced Materials Research, 2012, 518-523: 1406-1411.

[ 5 ] Cui XL. Investigation on pollution sources of eutrophication in Baiyangdian Lake. Environmental Science, 1995, (S1) : 1727. [崔秀丽. 白洋淀水体富营养化污染源调查. 环境科学, 1995, (S1) : 17-27.]

[ 6 ] Wang Y, Liu LS, Shu JM et al. Community structure of phytoplankton and the water quality assessment in Lake Baiyangdia. J Lake Sci, 2011, 23(4) : 575-580. DOI: 10.18307/2011.0413. [王瑜, 刘录三, 舒俭民等. 白洋淀浮游植物群 落结构与水质评价. 湖泊科学, 2011, 23(4): 575-580.]

[ 7 ] Hu GC, Dai JY, Xu ZC et al. Bioaccumulation behavior of polybrominated diphenyl ethers (PBDEs) in the freshwater food chain of Baiyangdian Lake, North China. Environment International, 2010, 36: 309-315.

[ 8 ] Li WH, Gao LH, Liu JM et al. Occurrence of antibiotics in water, sediments, aquatic plants, and animals from Baiyangdian Lake in North China. Chemosphere, 2012, 89: 1307-1315.

[ 9 ] Liu XH, Xu MQ, Yang ZF et al. Sources and risk of polycyclic aromatic hydrocarbons in Baiyangdian Lake, North China. Journal of Environmental Science and Health A, 2010, 45: 413-420.

[10] Zhao Y, Yang Z, Li Y. Investigation of water pollution in Baiyangdian Lake. China Procedia Environmental Sciences, 2010, (2) : 737-748.

[11] Wen CH. Determination on heavy metals and distribution of Baiyang Lake [ Dissertation]. Baoding: Hebei University, 2009. [温春辉. 白洋淀地区重金属的检测及分布 [学位论文]. 保定: 河北大学, 2009.]

[12] Chen CY, Pickhardt PC, Xu MQ et al. Mercury and arsenic bioaccumulation and eutrophication in Baiyangdian Lake, China. Water Air Soil Pollutant, 2008, 190(1-4) : 115-127.

[13] Cai YJ, Zhang EL, Liu EF et al. Spatio-temporal characteristics of heavy metal pollution and potential ecological risk in the sediments of Lake Yangzonghai, Yunnan Province. J Lake Sci, 2017, 29(5) : 1121-1133. DOI: 10.18307/2017.0510. [蔡艳洁, 张恩楼, 刘恩峰等. 云南阳宗海沉积物重金属污染时空特征及潜在生态风险. 湖泊科学, 2017, 29(5): 1121-1133. ]

[14] Yang Z, Li GB, Wang DW et al. Pollution and the potential ecological risk assessment of heavy metals in sediment of Baiyangdian Lake. Journal of Agro-Environment Science, 2005, 24(5): 945-951. [杨卓, 李贵宝, 王殿武等. 白洋淀底泥 重金属的污染及其潜在生态危害评价. 农业环境科学学报, 2005, 24(5) : 945-951.]

[15] Li BC, He LS, Yang M et al. Speciation and vertical distribution of heavy metals in sediments of Baiyangdian Lake. Environmental Science, 2012, 33(7) : 2376-2383. [李必才, 何连生, 杨敏等. 白洋淀底泥重金属形态及竖向分布. 环境 科学, 2012, 33(7) : 2376-2383.]

[16] Yang N, Yu HB, Song YH et al. Distribution of nitrogen and phosphorus in overlying water and pore water of sediment in Baitabuhe River. Reserach of Environmental Sciences, 2013, 26(7): 728-735. [杨楠, 于会涁, 宋永会等. 白塔堡河上 覆水与沉积物间隙水 N、P 分布特征. 环境科学研究, 2013, 26(7): 728-735.]

[17] Bai HJ, Zhao QQ, Lu JJ et al. Profile distribution of soil heavy metals in the paludification region of Baiyangdian Lake-A case study of Shaochedian Lake. Wetland Science, 2013, 11(2): 271-275. [白军红, 赵庆庆, 卢琼琼等. 白洋淀沼泽 化区域土壤重金属含量的剖面分布特征——以烧车淀为例. 湿地科学, 2013, 11(2): 271-275.]

[18] Hu GC, Xu MQ, Xu ZC et al. Pollution characteristic and potential risk assessment of heavy metals in surface sediment from Fuhe River. Journal of Agro-Environment Science, 2011, 30(1): 146-153. [胡国成, 许木启, 许振成等. 府河-白 洋淀底泥中重金属污染特征及潜在风险评价. 农业环境科学学报, 2011, 30(1)：146-153.]

[19] Xiao X, Lou LP, Li H et al. Algal control ability of allelopathically active submerged macrophytes: A review. Chinese Journal of Applied Ecology, 2009, 20(3): 705-712. [肖溪, 楼莉萍, 李华等. 沉水植物化感作用控藻能力评述. 应 用生态学报, 2009, 20(3): 705-712.]

[20] Pan YH, Wang HB, Gu ZP et al. Accumulation and translocation of heavy metals by macrophytes. Acta Ecologica Sinica, 2010, 30(23) : 6430-6441. [潘义宏, 王宏镔, 谷兆萍等. 大型水生植物对重金属的富集与转移. 生态学报, 2010, $30(23): 6430-6441$. 
[21] Xu F, Yang ZF, Chen B et al. Impact of submerged plants on ecosystem health of the plant-dominated Baiyangdian Lake, China. Ecological Modelling, 2013, 252: 167-175.

[22] Xing W, Wu HP, Hao BB et al. Bioaccumulation of heavy metals by submerged macrophytes: Looking for hyperaccumulators in eutrophic lakes. Environmental Science \& Technology, 2013, 47(9) : 4695-4703.

[23] Xue PY, Li GX, Liu WJ et al. Copper uptake and translocation in a submerged aquatic plant Hydrilla verticillata ( L.f.) Royle. Chemosphere, 2010, 81(9) : 1098-1103.

[24] Zheng K, Zhao QL, Geng LP et al. Effects of exogenous bacterial inoculants on silicon and arsenic availability in As-contaminated paddy soil under different water regimes. Journal of Soil and Water Conservation, 2015, 29(3) : 262-271. [郑 坤, 赵全利, 耿丽平等. 不同水分条件下外源菌剂对污染水稻土中硅、砷有效性的影响. 水土保持学报, 2015,29 (3) : 262-271.]

[25] Müller G. Index of geoaccumulation in sediments of the Rhine River. Geojournal, 1969, 2(3) : 108-118.

[26] State Bureau of Environmental Protection ed. Background values of soil elements in China. Beijing: China Environment Science Press, 1990. [ 国家环境保护总局. 中国土壤元素背景值. 北京: 中国环境科学出版社, 1990.]

[27] Hakanson L. An ecological risk index for aquatic pollution control. A sedimentological approach. Water Research, 1980,14 (8) : 975-1001.

[28] Wang YQ, Xue PY, Geng LP et al. Distribution characteristic of nitrogen and phosphorus in sediments- submerged macrophytes-water systems of Baiyangdian Lake. Journal of Soil and Water Conservation, 2017, 31(3) : 304-309. [王亚琼, 薛 培英, 耿丽平等, 白洋淀沉积物-沉水植物-水系统氮、磷分布特征. 水土保持学报, 2017, 31(3): 304-309.]

[29] Zhang XG, Liu SQ, Dou TL et al. Strategies for controlling water environmental pollution in the area of Baiyangdian Lake. Chinese Journal of Eco-Agriculture, 2006, 14(2) : 27-31. [张笑归, 刘树庆, 窦铁岭等. 白洋淀水环境污染防治对策. 中国生态农业学报, 2006, 14(2): 27-31.]

[30] Kong JX, Jiang RN, Fan BB et al. Research and management of agricultural non- point source pollution. Environmental Science and Management, 2016, 41(5) : 85-88. [孔嘉金美, 仁楠, 范贝贝等. 农业面源污染特征及治理对策. 环境 科学与管理, 2016, 41(5): 85-88.]

[31] Chen Y, Cheng W, Shi M et al. The distribution feature of the pollutants in sediment pore water and overlying water of Shaanxi segment in Weihe River. Journal of Water Resources and Water Engineering, 2017, 28(1) : 50-55. [ 陈瑶, 程文, 石苗等. 渭河陕西段底泥间隙水与上覆水中污染物分布特征研究. 水资源与水工程学报, 2017, 28(1) : 50-55.]

[32] Luo YH, Nie XQ, Li X et al. Distribution and emission flux estimation of phosphorus in the sediment andinterstitial water of Xiangxi River. Environmental Science, 2017, 38(6): 2345-2354. [罗玉红, 聂小倩, 李晓等. 香溪河沉积物、间隙 水的磷分布特征及释放通量估算. 环境科学, 2017, 38(6): 2345-2354.]

[33] Qin YW, Han CN, Zhang L et al. Distribution of heavy metals among surface water, suspended solids and surface sediments in Hengyang section of Xiangjiang River. Acta Scientiae Circumstantiae, 2012, 32(11): 2836-2844. [秦延文, 韩 超南, 张雷等. 湘江衡阳段重金属在水体、悬浮颗粒物及表层沉积物中的分布特征研究. 环境科学学报, 2012,32 (11) : 2836-2844.]

[34] Shi CJ, Li HX, Zhang Y et al. Distribution characteristics of heavy metals in overlying water-pore water-sediment in the Yongding River. Environmental Chemistry, 2017, 36(1): 48-61. [时春景, 李红霞, 张言等. 永定河上覆水、间隙水和 沉积物中重金属的分布特征. 环境化学, 2017, 36(1): 48-61.]

[35] Tian LF, Hu JW, Qin PX et al. Distribution of heavy metal elements in the water body from Lake Hongfeng. China Environmental Science, 2011, 31(3): 481-489. [田林锋, 胡继伟, 秦栎金等. 重金属元素在贵州红枫湖水体中的分布 特征. 中国环境科学, 2011, 31(3): 481-489.

[36] Lei Y, Wang PF, Wang C et al. The effect of submerged plants on the release of heavy metal from sediment under different hydrodynamic disturbances. Journal of Hydrodynamics, 2015, 30(3) : 245-250. [雷阳, 王佩芳, 王超等. 不同水动力 扰动下沉水植物对底泥重金属释放的影响. 水动力学研究与进展, 2015, 30(3): 245-250.]

[37] Gray C, McLaren R, Roberts A. Atmospheric accessions of heavy metals to some New Zealand pastoral soils. Science of the Total Environment, 2003, 305: 105-115.

[38 ] Sabin LD, Lim JH, Stolzenbach KD et al. Atmospheric dry deposition of trace metals in the coastal region of Los Angeles, California, USA. Environmental Toxicology and Chemistry, 2006, 25: 2334-2341.

[39] Guo W, Pei YS, Yang ZF et al. Historical changes in polycyclic aromatic hydrocarbons (PAHs) input in Lake Baiyangdi- 
an related to regional socio-economic development. Journal of Hazardous Materials, 2011, 187: 441-449.

[40] Yao LX, Huang LX, Jiang ZY et al. Investigation of As, Cu and Zn species and concentrations in animal feeds. Environmental Science, 2013, 32(2) : 732-739. [姚丽贤, 黄连喜, 蒋宗勇等. 动物饲料中砷、铜和锌调查及分析. 环境科 学, 2013, 32(2): 732-739.]

[41] Jiang YS, Chen H, Ma ZM et al. Field study on effect of harvesting submerged plant during growing season for ecological management of eutrophicated water. Chinese Journal of Environmental Engineering, 2013, 7 (4) : 1351-1358. [姜义帅, 陈影, 马作敏等. 利用沉水植物生长期收割进行富营养化水体生态管理的实地研究. 环境工程学报, 2013, 7(4): 1351-1358. ]

[42] Xu F, Yang ZF, Chen B et al. Ecosystem health assessment of Baiyangdian Lake based on thermodynamic indicators. Procedia Environmental Sciences, 2012, 132: 2402-2413.

[43] Zhang N, Wei CY, Yang LS. Occurrence of arsenic in two large shallow freshwater lakes in China and a comparison to other lakes around the world. Microchemical Journal, 2013, 110: 169-177.

[44] Xue PY, Yan CZ, Sun GX et al. Arsenic accumulation and speciation in the submerged macrophyte Ceratophyllum demersum L. Environmental Science and Pollution Research, 2012, 19: 3969-3976.

[45] Cui C, Cai JB, Hua YM et al. Purification of combined pollution of heavy metals in micro contaminated water by Potamogeton crispus L.. Journal of Huazhong Agricultural University, 2014, 33(2) : 72-77. [崔晨, 蔡建波, 华玉妹等. 菹草 对微污水中重金属复合污染的净化效果. 华中农业大学学报, 2014, 33(2): 72-77.]

[46] Zu YQ, Li Y, Bock L et al. Interactions between heavy metals and nitrogen and their ecological effects. Journal of Agro-envrionment Science, 2008, 27 (1) : 7-14. [祖艳群, 李元, Bock L 等. 重金属与植物 N 素营养之间的交互作用及其生 态学效应. 农业环境科学学报, 2008, 27(1):7-14.]

[47] Qiu Q, Wang YT, Yang ZY et al. Effects of phosphorus supplied in soil on subcellular distribution and chemical forms of cadmium in two Chinese flowering cabbage (Brassica parachinensis L.) cultivars differing in cadmium accumulation. Food and Chemical Toxicology, 2011, 49: 2260-2267.

[48] Yang YJ, Xiong J, Chen RJ et al. Excessive nitrate enhances cadmium ( Cd) uptake by up-regulating the expression of OsIRT1 in Rice (Oryza sativa). Environmental and Experimental Botany, 2016, 122 : 141-149. 